\title{
Prevention of Acute Malnutrition During the Lean Season: Comparison of a Lipid-Based Nutrient Supplement and an Improved Dry Ration, South Darfur, Sudan. A quasi-Experimental Study
}

Leisel Talley $^{1 *}$, ErinBoyd ${ }^{2}$, Fawzia el Sharief ${ }^{3}$, CurtisBlanton ${ }^{4}$, Mohamed OmerAli ${ }^{5}$ and Maha Mohamed Omer AbdEl rahman ${ }^{6}$

${ }^{1}$ Centers for Disease Control and Prevention, 1600 Clifton Road, MS F60 Atlanta, GA 30333, USA

2United Nations Children's Fund, UNICEF HQ Room 842, 3 UN Plaza, New York City, New York 10017, USA

${ }^{3}$ United Nations Children's Fund- Nyala Office, P.O. Box 1358 - Khartoum Sudan, Sudan

${ }^{4}$ Centers for Disease Control and Prevention, 1600 Clifton Road, MS F60 Atlanta, GA 30333, USA

${ }^{5}$ Nutrition Diploma, State Ministry of Health, Nutrition Directorate Office, opposite Nyala Teaching Hospital, Nyala, South Darfur, Sudan

${ }^{6}$ State Ministry of Health, Nutrition Directorate Office, opposite Nyala Teaching Hospital, Nyala, South Darfur, Sudan

\begin{abstract}
Objective: To assess the nutritional impact of a Lipid-Based Nutrient Supplement (LNS) and an Improved Dry Ration (IDR) in blanket supplementary feeding programs.
\end{abstract}

Design: Longitudinal, quasi experimental non-randomized study

Setting: Otash and Al Salaam internally displaced persons camps, South Darfur, Sudan

Subjects: Children aged 6-36 months were randomly selected for inclusion in the study based on height cut-off of $95 \mathrm{~cm}$ and were anthropometrically assessed (weight-for-height $z$ scores [WHZ] based on WHO standards, edema presence, and midupper arm circumference) monthly. IDR was distributed in Otash camp and LNS in AI Salaam.

Main findings: At baseline, 658 and 893 children were enrolled and 159 and 187 children were assessed at all 4 distributions in Otash and AI Salaam camps, respectively; There was no significant difference in mean WHZ between the two groups at baseline, (Otash=-1.18 and Al Salaam $=-1.03, p=0.17)$. Children receiving LNS had higher mean WHZ than those receiving IDR. Significant differences were detected at months $2-4$, for the mean WHZ of the LNS cohort, and at 4 months, for the difference of the difference in mean WHZ $(-0.23)$ between camps, $p=0.02$.

Conclusions: LNS may be an option for preventing acute malnutrition in humanitarian settings, however research is needed on the timing, duration of use and cost effectiveness.

Keywords: Acute malnutrition; Blanket feeding; Lipid Based Nutrient Supplement (LNS); Ready to Use Foods (RUF)

\section{Introduction}

Acute malnutrition, defined as a Weight-for-Height $\mathrm{Z}$ score (WHZ) of <-2 (WHO growth standards)and/or presence of bilateral pitting edema, among children under five years of age is a significant public health concern, with an estimated 50 million children suffering each year and 1 million children dying from the most severe form [1]. Globally between 36 and 41 million children suffer from moderate acute malnutrition (WHZ $\geq-3$ and $<-2$ ) and have a 3 times increased risk for mortality compared to well nourished children [1,2]. Moderate acute malnutrition accounts for the majority of malnutrition associated deaths [1]. In humanitarian contexts, the situation is often exacerbated by food shortages, increased risk of infectious diseases, and the impact of conflict and resulting insecurity, which results in reduced access to affected populations.

In many countries there are seasonal variations in acute malnutrition, where the prevalence increases two-or- three-fold in the months immediately preceding the harvest. This period often coincides with the rainy season where the incidence of diarrheal disease, respiratory infection and malaria increase forming a synergistic relationship with food shortages, ultimately increasing the incidence of acute malnutrition $[3,4]$. In South Darfur, Sudan, July and August represent the peak of the lean season when the prevalence of acute malnutrition doubles and often exceeds the nutritional threshold for an emergency $[4,5]$.

Blanket Supplementary Feeding (BSF) programs, commonly implemented in emergencies, provide a supplementary food ration to all members of a vulnerable population (children under five years of age) with the objective to prevent acute malnutrition. BSF is a population level intervention that uses food to produce a desired nutritional outcome; typically there is no individual assessment or follow-up outside of the initial registration and screening [2].

Darfur has been mired in conflict, insecurity and mass displacement since 2003. In 2009, at the time of this pilot program there were nearly 4.7 million conflict-affected persons of whom 2.7 million were internally displaced persons (IDP) [6]. While IDPs were largely reliant on World Food Programme (WFP) food distributions, security permitting, a small proportion of IDPs continued to farm their land in the surrounding area. This agricultural output served as an important supplement to both the diet and income of the IDPs. Despite the presence of a general food ration, malnutrition rates increased appreciably during the lean season. To counter this effect, UNICEF and partners instituted BSF programs in IDP camps across Darfur, including $\mathrm{Al}$ Salaam and Otash camps. In the preceding years (2007-

*Corresponding author: Leisel Talley, International Emergency and Refugee Health Branch, Center for Global Health, Centers for Disease Control and Prevention. 1600 Clifton Road, MS F60 Atlanta, GA 30333. Tel. 1770.488 .0696 Fax: +1 770. 488.3266; E-mail: Ltalley@cdc.gov

Received June 20, 2012; Accepted July 12, 2012; Published July 14, 2012

Citation: Talley L, Boyd E, el Sharief F, Blanton C, OmerAli M, et al. (2012) Prevention of Acute Malnutrition During the Lean Season: Comparison of a LipidBased Nutrient Supplement and an Improved Dry Ration, South Darfur, Sudan. A quasi-Experimental Study. J Nutr Disorders Ther 2:117. doi:10.4172/21610509.1000117

Copyright: $\odot 2012$ Talley L, et al. This is an open-access article distributed under the terms of the Creative Commons Attribution License, which permits unrestricted use, distribution, and reproduction in any medium, provided the original author and source are credited. 
Citation: Talley L, Boyd E, el Sharief F, Blanton C, OmerAli M, et al. (2012) Prevention of Acute Malnutrition During the Lean Season: Comparison of a Lipid-Based Nutrient Supplement and an Improved Dry Ration, South Darfur, Sudan. A quasi-Experimental Study. J Nutr Disorders Ther 2:117. doi:10.4172/2161-0509.1000117

Page 2 of 5

2008), the BSF program did not seem to be effective at preventing large-scale acute malnutrition during the lean season in these 2 camps. In 2008, the prevalence of global acute malnutrition (WHZ $<-2$ and/or edema cases) increased from $7.4 \%$ (95\% CI 5.3-10.3) to $19.2 \%$ (95\% CI: 15.7- 23.1) and 9.8\% (95\% CI: 7.3- 12.9) to $19.5 \%$ (95\% CI: $16.1-23.5)$ in Al Salaam and Otash camps, respectively between harvest and the lean season $[4,5,7]$.

Fortified Blended Flour (FBF), usually Corn Soy Blend (CSB), mixed with oil and sugar is the standard ration for BSF [8]. Over twenty years of programmatic implementation, a number of issues have been identified with the use of FBF in young children including: low energy density to stomach capacity of a child; a high phytate concentration, which inhibits the absorption of iron; low fat and essential fatty acid levels; a lack of required nutrients in sufficient amounts; a lack of animal protein; and low acceptability by the local population of the FBF [9]. FBF requires further preparation to make a porridge through the addition of water and cooking for 5 to 10 minutes to kill bacteria [9]. Contamination can occur if the FBF porridge is left out and consumed throughout the day.

Ready to use foods in the form of Lipid-Based Nutrient Supplements (LNS) offer a potential alternative to traditional FBF for the prevention of acute malnutrition. LNS is a high energy and nutrient dense paste, which contain essential fatty acids and a complement of micronutrients to promote growth in young children. These products have low moisture content and therefore the risk of microbial contamination is reduced. LNS can be stored without refrigeration and consumed without further preparation. Children consume 46 grams or 3 teaspoons, 3 times per day [10]. [Guidance on the production and use of ready to use products is still under development. At the time of this evaluation, the commercial product procured was Plumpy'doz $z^{\oplus}$ and it was considered to be a LNS and therefore the authors have retained this nomenclature]

While LNS has been piloted for the treatment of moderate acute malnutrition and used in limited settings for BSF, no data had been collected on the impact of the LNS in BSF programs in preventing new cases of acute malnutrition associated with lean season in IDP camps [11- 14].In 2009, in an effort to improve the outcome of BSF programs in South Darfur, UNICEF piloted the use of LNS and Improved Dry Ration (IDR) of FBF, oil, sugar and dried skim milk in BSF programs. UNICEF, the World Food Programme (WFP), World Vision International, the State Ministry of Health in South Darfur (MOH), and the US Centers for Disease Control and Prevention assessed the nutritional impact of these two alternative rations in a BSF program through a longitudinal cohort of children aged 6 to 36 months.

\section{Materials and Methods}

\section{Study design}

A longitudinal, quasi experimental, non-randomized study of children aged 6 to 36 months receiving BSF rations was conducted between May and August 2009, in South Darfur. Otash and Al Salaam camps are close to Nyala town (20 kilometers), the administrative capital of South Darfur. At the time of the intervention, there were approximately 70,134 and 62,876 IDPs and 14,027 and 12,575 children under five years of age residing in Otash and Al Salaam camps, respectively. The camps were also comparable in terms of services provided: water, sanitation and hygiene, primary health care and treatment of severe acute malnutrition and a general food ration. Al Salaam camp was assigned to receive the LNS and Otash camp was assigned to receive the IDR. Security constraints and ethical considerations prevented randomization within camps. The BSF program provided monthly supplementary rations from May through August 2009. Distributions were conducted on a monthly basis within each geographic sector of the camps.

Prior to the start of the BSF program, all children under five years of age residing in each camp were registered to determine the total number of beneficiaries. Children less than $95 \mathrm{~cm}$ (the height proxy for children aged 6 to 36 months ) were the target group for the pilot due to higher rates of malnutrition and the greater potential impact of acute malnutrition on growth and development. Height was used as a proxy for age because of the absence of health and birth records. From the children less than $95 \mathrm{~cm}$, a sampling interval of every $6^{\text {th }}$ child was calculated and used to randomly select children for inclusion until the sample size in each camp was achieved.

\section{Intervention}

The BSF program in Otash camp provided a monthly 5 kilogram ration of IDR, which consisted of: CSB (120 gm), dried skim milk powder $(20 \mathrm{gm})$, oil $(20 \mathrm{gm})$ and sugar $(20 \mathrm{gm})$ or $180 \mathrm{gm}$ per day. CSB is a blend of partially precooked and milled cornmeal, soy flour, and soybean oil that is fortified with micronutrients $[15,16]$. CSB, dried skim milk powder and sugar were mixed and packaged prior to distribution to minimize selling of specific components. Vegetable oil was packaged separately to prolong the shelf-life of the IDR. The IDR provided 785 kilocalories per day, 28.8 grams of protein and 27.4 grams of fat (Table 1).

The BSF program in Al Salaam provided a monthly ration of Plumpy'doz ( Nutriset, Malaunay, France), a LNS. Plumpy'doz contains peanut paste, vegetable fat, skimmed milk powder, whey, maltodextrines, sugar and Complex of Minerals and Vitamins ${ }^{\circ}$ [15] Beneficiaries received 4 pots per month; each pot contained a weekly ration. The LNS ration provided 247 kilocalories per day, 5.9 grams of protein and 16 grams of fat (Table 1). Children were to consume 46 grams or three spoonfuls of the LNS, three times per day [10].

Communication and sensitization campaigns were implemented in both camps regarding the purpose and use of the rations, including the importance of not sharing the ration with non-targeted individuals in the household. Cooking demonstrations were held for households receiving the IDR.

\section{Measurements}

Anthropometric measurements were obtained on a monthly basis during the ration distribution. Height (length if $<87 \mathrm{~cm}$ ) was measured

\begin{tabular}{|c|c|c|}
\hline & $\begin{array}{c}\text { Lipid-based Nutrient } \\
\text { Supplement }\end{array}$ & Improved Dry Ration \\
\hline Daily ration size $(\mathrm{g})$ & 46.3 & 180 \\
\hline Energy & 247 & 785 \\
\hline Fat $(\mathrm{g})$ & 16.0 & 27.4 \\
\hline Protein $(\mathrm{g})$ & 5.9 & 28.8 \\
\hline Calcium $(\mathrm{mg})$ & 387 & 473 \\
\hline Iron $(\mathrm{mg})$ & 9 & 15.4 \\
\hline Iodine $(\mu \mathrm{g})$ & 90 & 2 \\
\hline Vitamin A $(\mu \mathrm{g}$ RE) & 400 & 783 \\
\hline Thiamin $(\mathrm{mg})$ & 0.5 & 0.60 \\
\hline Riboflavin $(\mathrm{mg})$ & 0.5 & 1.16 \\
\hline Niacin $(\mathrm{mg} \mathrm{NE})$ & 0.5 & 13.8 \\
\hline Vitamin C $(\mathrm{mg})$ & 30 & 62 \\
\hline
\end{tabular}

Table 1: Nutritional composition of lipid-based nutrient supplement and improved dry ration. 
to the nearest $0.1 \mathrm{~cm}$ using Shorr boards (Shorr Products, Orney, Maryland) and standard techniques[17, 18]. Weight was measured to the nearest $0.1 \mathrm{~kg}$ using Seca scales (UNICEF Warehouse, Copenhagen, Denmark). Mid Upper Arm Circumference (MUAC) was measured to the nearest millimeter on the left arm using UNICEF non-stretchable calibrated tapes. Children were also assessed for the presence of bilateral pitting edema, a clinical sign of Kwashiorkor, a form of severe acute malnutrition and were referred for appropriate treatment if they met admission criteria. Pre-existing surveillance teams and $\mathrm{MOH}$ mobilization teams experienced in anthropometric assessment (6 teams of 3 measurers) in each camp were provided refresher training with a standardization activating and carried out monthly anthropometric assessments. If a child was absent during the monthly anthropometric measurements, the team's first communicated with sheikhs to trace the child. When possible, teams attempted three home visits to locate the child for each measurement, always with a sheikh. In addition to monthly anthropometric measurements, 15 days after LNS distribution, $\mathrm{MOH}$ teams visited 30 households to collect information on recent illness, receipt, consumption and perception of LNS. These data are reported elsewhere.

\section{Statistical Analysis}

Sample size calculations were calculated based on a method by Diggle for repeated measures longitudinal analysis [19]. The assumption was that the mean weight for height (WHZ) for the IDR camp would decrease over time indicating deterioration in nutritional status. Assuming a small within subject correlation of 0.3 , a conservative effect size of 0.1 , a power of $80 \%$ and an alpha of 0.05 , a defaulting rate of $30 \%$ based upon historical programmatic data and the mobility of the population, the sample size was 677 children per camp [20]. If the caretaker agreed to participate in the follow-up activities, the child was marked with indelible ink on their fingernail to denote their enrollment. Anthropometric measurements (weight, height, MUAC and age) were taken on each participant and recorded on site using Epi Info software [21]. Children with chronic illness, cardiac disease, congenital abnormalities or cancer, were not eligible for the study; children with signs of severe acute malnutrition, including a MUAC $<115 \mathrm{~mm}$ or edema were ineligible as well and were referred for appropriate treatment.

Monthly anthropometric data were entered into EPI Info Version 3.5.1 and Emergency Nutrition Assessment software (http://www.cdc. gov/globalhealth/ierh/ResearchandSurvey/enasoftware.htm) used to generate anthropometric indices, specifically weight-for-height based on World Health Organization Growth Standards [22,23]. Values outside of the range of $+/-4 \mathrm{WHZ}$ were excluded from the analysis. All other analysis was carried out in $\mathrm{SAS}^{\oplus}$ version 9.2 software (SAS Institute Cary, NC). The SAS procedure PROC MIXED was used for the analysis and the contrast statement was used to test the difference in differences between two time periods [24, 25]. Various covariance structures were fit using the mixed procedure and the unstructured matrix provided the best fit, so no random effects were used in the analysis. A $P<0.05$ was considered significant. Additional analysis using the SAS procedure PROC MI with Markov Chain Monte Carlo simulation was used to impute data for missing values among those loss to follow-up.

Only children with weight and length/height measurements at 4 time points were included in the analysis. Mean WHZ and standard deviations were calculated for each group (LNS and IDR) at each time point. The difference in mean WHZ between groups at each time point were tested for statistical difference using a $t$ test for comparing two group means. We made the following assumptions: the observations were independent; observations for each group were a random sample from a population with a normal distribution, and variances for the two independent groups are equal.

A difference in differences approach was used in measuring the change in the WHZ from baseline to each distribution time period between the two camps. The difference in differences method takes the average change in WHZ between two time periods for the LNS group and compares it to the average change in WHZ for the IDR group [26] The only confounder adjusted for in the analysis was sex.

\section{Ethics}

The study was reviewed and approved by the Federal Ministry of Health Research Council, Health Research Technical Committee in Sudan. Additionally, the CDC determined that the activity was not human subjects research and that the primary intent was public health practice or a disease control activity. The Humanitarian Aid Commission (HAC) of South Darfur also participated and consented to the activities. Approval from the sheikhs in each camp was sought prior to the start of blanket distribution. The purpose of the activities was explained to the primary caregiver (usually the mother) of the children selected to participate in the follow-up assessment and informed verbal consent was obtained for all enrolled children. If informed consent was not granted, children continued to receive the ration, but were not included in follow-up activities. All children found to be severely malnourished during the course of the program were referred to treatment in their respective camp. Research assistants not involved in the production or marketing of either product implemented the study participant selection process.

\section{Result}

At the time of enrollment, 658 (Otash camp) and 893 children (Al Salaam camp), with weight and height measurements were registered to receive IDR and LNS respectively. The refusal of the BSF program by a sheikh in one camp section of Otash camp during the first distribution resulted in fewer children enrolled compared with Al Salaam. Analysis revealed, 43 (IDR) and 68(LNS) severely malnourished children based on $\mathrm{WHZ}<-3$ not identified by MUAC at enrollment. These children were excluded from further analysis as the objective was to assess prevention of acute malnutrition. MUAC and WHZ do not always classify the same child as malnourished and thus the reason for the discrepancy.

The number of children attending distributions was variable, with the largest absolute decrease in attendance observed at the second distribution. Thirty-six percent and $54 \%$ of children defaulted (or failed to appear for the distribution) from the first to second distribution (Table 2). Only children with measurements at all 4 time distributions were included, 187 and 159 children the IDR and LNS cohorts, respectively.

At enrollment, the cohort of children in IDR and LNS cohorts were similar. There was no statistical difference in the mean age or sex of children ( $\mathrm{p}=0.72$ and $\mathrm{p}=0.24$, respectively) (Table3). Additionally, there was no statistical difference in the mean WHZ scores at enrollment, $\mathrm{IDR}=-1.18$ and $\mathrm{LNS}=-1.03, \mathrm{p}=0.17$ (Table 4). However, at the second distribution there was a statistical difference in the mean WHZ with the LNS group having a higher mean WHZ (IDR $=-1.23 \mathrm{LNS}=-0.94$, $p$ value $=0.014)$. At each of the subsequent distributions, there was a significant difference in the mean WHZ.

The analysis of the difference of the differences in mean WHZ 
Citation: Talley L, Boyd E, el Sharief F, Blanton C, OmerAli M, et al. (2012) Prevention of Acute Malnutrition During the Lean Season: Comparison of a Lipid-Based Nutrient Supplement and an Improved Dry Ration, South Darfur, Sudan. A quasi-Experimental Study. J Nutr Disorders Ther 2:117. doi:10.4172/2161-0509.1000117

Page 4 of 5

between baseline and each subsequent distribution between the two camps showed no statistical difference from baseline to distribution 2 or 3 (Table 5). However, the average change in mean WHZ compared between cohorts was significantly different between baseline and distribution 4 , mean $\mathrm{WHZ}=0.23$ and $\mathrm{p}=0.02$; the change was larger in the LNS cohort (Table 4). Each of the cohorts evolved differently; the mean WHZ in the LNS cohort improved indicating an increase in nutritional status while there was a slight deterioration in nutritional status in the mean WHZ in the IDR cohort.

Further analysis of baseline data was conducted to assess potential differences between children attending all four distributions (nondefaulters) and defaulters (those attending less than 4 distributions). At baseline, there was no difference among defaulters and non-defaulters in the sex distribution in either the LNS or IDR cohorts (LNS: chisq= 0.22 and $\mathrm{p}=-.64$, IDR: chisq $=0.2$ and $\mathrm{p}=0.66$ ), mean WHZ (LNS: $\mathrm{t}$-test $=$ $1.68 \mathrm{p}=0.09$; IDR: $\mathrm{t}$-test $=0.53 \mathrm{p}=0.6$ ), or mean age (LNS: $\mathrm{t}$-test $=1.68$ and $\mathrm{p}=0.09$; IDR: $\mathrm{t}$-test $=1.41 \mathrm{p}=0.16$ ). Additionally, Proc $M I$ was used to impute missing data and create multiple imputations. We found no difference in the outcomes in the main analysis when imputed data was included.

\section{Discussion}

In contexts where a large-scale preventative intervention is needed, LNS may be an option for the prevention of seasonal acute malnutrition in food-aid dependent camp populations. Among children regularly attending monthly distributions, LNS performed slightly better than IDR from a statistical perspective; however, the mean WHZ among children receiving IDR was also maintained over the 4 month period without significant deterioration. Programmatically, the benefit of LNS in terms of a statistically significant difference in the mean WHZ is not easily translated into reduced burden of disease. LNS do not need to be cooked, which makes it a more convenient commodity for households. The main limitations were related to security, logistics,

\begin{tabular}{|c|c|c|}
\hline & $\begin{array}{l}\text { Lipid-based Nutrient } \\
\text { Supplement }\end{array}$ & Improved Dry Ration \\
\hline & Number (Defaulting Rate \%) & Number (Defaulting Rate \%) \\
\hline Distribution 1 & $893(\mathrm{NA})$ & $658(\mathrm{NA})$ \\
\hline Distribution 2 & $412(53.9)$ & $421(36.0)$ \\
\hline Distribution 3 & $341(61.8)$ & $312(52.6)$ \\
\hline Distribution 4 & $353(60.5)$ & $418(36.5)$ \\
\hline $\begin{array}{l}\text { Excluded } \\
\text { malnourished at } \\
\text { enrollment }\end{array}$ & 68 & 43 \\
\hline $\begin{array}{l}\text { Total with } 4 \\
\text { measurements }\end{array}$ & 159 & 187 \\
\hline
\end{tabular}

Table 2: Cohort attendance and defaulting rates at each distribution in Lipid-based Nutrient Supplement and Improved Dry Ration groups, May through August 2009.

\begin{tabular}{|c|c|c|c|}
\hline Intervention & $\begin{array}{l}\text { Lipid-based Nutrient } \\
\text { Supplement } \\
N=159\end{array}$ & $\begin{array}{l}\text { Improved Dry } \\
\text { Ration } \\
N=187\end{array}$ & \\
\hline & Number (\%) & Number (\%) & \\
\hline Boys & $47.17 \%$ & $53.48 \%$ & \multirow{2}{*}{$\begin{array}{c}\text { Chi Square }=1.37 \\
\text { p value }=0.24\end{array}$} \\
\hline Girls & $52.83 \%$ & $46.52 \%$ & \\
\hline $6-11$ months of age & $12(7.6)$ & $20(10.7)$ & \\
\hline $12-23$ months of age & $52(32.7)$ & $61(32.6)$ & \\
\hline $24-36$ months of age & $95(59.7)$ & $106(56.7)$ & \\
\hline $\begin{array}{c}\text { Mean Age in months } \\
\text { (range) }\end{array}$ & $24.03(6-36)$ & $23.70(6-36)$ & \multirow{2}{*}{$\begin{array}{l}\text { T-test }=-0.36 \\
\text { value }=0.72\end{array}$} \\
\hline Standard Deviation & 8.2 & 8.3 & \\
\hline
\end{tabular}

Table 3: Demographics of cohort at enrollment, Lipid-based Nutrient Supplement and Improved Dry Ration groups, May 2009.

\begin{tabular}{|c|c|c|c|}
\hline Distribution & $\begin{array}{c}\text { Lipid-based Nutrient } \\
\text { Supplement } \\
\text { Mean }(95 \% \mathrm{Cl}) \\
\mathrm{N}=159\end{array}$ & $\begin{array}{c}\text { Improved Dry Ration } \\
\text { Mean }(95 \% \mathrm{Cl}) \\
\mathrm{N}=187\end{array}$ & P value \\
\hline 1 & $\begin{array}{c}-1.03 \\
(-1.18,-0.88)\end{array}$ & $\begin{array}{c}-1.18 \\
(-1.33,-1.03)\end{array}$ & 0.17 \\
\hline 2 & $\begin{array}{c}-0.94 \\
-1.23\end{array}$ & 0.014 \\
\hline 3 & $(-1.10,-0.79)$ & $(-1.39,-1.07)$ & 0.013 \\
\hline 4 & $\begin{array}{c}-1.21 \\
(-1.9 .93\end{array}$ & $\begin{array}{c}-1.22 \\
(-0.77)\end{array}$ & 0.001 \\
\hline
\end{tabular}

Table 4: Mean weight for height $Z$ score by cohort at each distribution, May through August 2009

\begin{tabular}{|c|c|c|}
\hline Distribution interval & $\begin{array}{c}\text { Mean Difference } \\
\text { (Standard Deviation) }\end{array}$ & P Value \\
\hline 1 to 2 & $0.13(0.92)$ & 0.25 \\
\hline 1 to 3 & $0.13(0.89)$ & 0.19 \\
\hline 1 to 4 & $0.23(0.91)$ & 0.02 \\
\hline
\end{tabular}

Table 5: The Difference in the difference of mean weight for height $Z$ score of the cohorts between distribution 1 and subsequent distributions.

and communication. Expulsion of the main non-governmental organization providing nutrition services in both camps two months prior to the beginning of the lean season resulted in limited capacity to implement this program. Security and capacity constraints prohibited implementing an ideal study where multiple camps and/or children would have been randomized to receive the interventions and then evaluated. Ethically, it was not possible to have a control group that did not receive a ration.

Defaulting is common in all feeding programs, curative or preventive, and has been a particular challenge in Darfur [21]. As this operational research was not an evaluation of the implementation of the BSF program, reasons for defaulting were not specifically measured. In normal BSF programs, children are individually assessed during the registration period, which is often the first distribution. In subsequent distributions, the children are not required to attend for logistics reasons, and therefore the caretaker normally receives the ration by providing a card or other evidence of enrollment. The pilot program only required monthly measurements of the children in the cohort (a small fraction of the total beneficiaries) and logistic constraints required that rations be provided to the caregiver even if the enrolled child was not at the distribution. Defaulting was apparent with a large drop in attendance between the first and second distribution, with the level of defaulting more significant in the LNS camp. One possible explanation for the higher defaulting in the LNS camp may be a result of confusion around the number of distributions of LNS. Despite a communication campaign, some households believed that it was a one-time distribution. A second reason for the higher defaulting in the LNS camp is the mobility of the population; during the pilot program security had slightly improved granting a small proportion of IDPs access to land during the cultivation period. Mothers carried their youngest children with them to the fields for weeks at a time missing single or multiple distributions. Another member of the household may have picked up the ration; however, the registered child did not attend the distribution and may have not benefited from the ration. This significant level of defaulting may have introduced bias. Finally, the lack of recognition of moderate acute malnutrition as a significant health issue, reducing the inherent perceived value of the program and leading to a further decline in attendance may have influenced defaulting [27]. While defaulting was significant in both cohorts, analysis did not show any anthropometric or demographic difference 
Citation: Talley L, Boyd E, el Sharief F, Blanton C, OmerAli M, et al. (2012) Prevention of Acute Malnutrition During the Lean Season: Comparison of a Lipid-Based Nutrient Supplement and an Improved Dry Ration, South Darfur, Sudan. A quasi-Experimental Study. J Nutr Disorders Ther 2:117. doi:10.4172/2161-0509.1000117

Page 5 of 5

at time of enrollment between defaulters and non-defaulters, however, the reason for defaulting and the nutritional status of individual defaulters is unknown.

There are a number of outstanding programmatic and operational questions surrounding the use of LNS for the prevention of acute malnutrition that require further research. The optimal timing of implementing BSF, either LNS or a FBF based ration, is unknown. There may be benefits in weight maintenance linked to the timing of initiation of the intervention. For example, children may have a greater benefit in weight maintenance if the intervention commences 1 or 2 months prior to the start of the lean season. The second question is how long children should be supplemented to achieve the greatest nutritional impact. The duration of supplementation relates to both the individual nutritional level but also addresses programmatic and resource issues. It is essential for programs to be designed to achieve their objectives, but also to use resources (human and financial) in the most efficient manner. Access to a population, information, communication and educational components of any program are critical and should be properly evaluated to assess their contribution to preventing acute malnutrition [28].

\section{Acknowledgments}

We would like to acknowledge the contribution of ACF France for their original research concept. Their insight and programmatic fortitude laid the groundwork for the entire pilot program process. Samir Wanamali from the World Food Programme in Sudan was an essential part of the program team and we are thankful for his time and commitment. We would also like to acknowledge the State Ministry of Health and World Vision teams in Otash and Al Salaam camps who were responsible for the monthly measurements of children enrolled in the pilot program. Finally, we gratefully acknowledge the displaced persons, mothers and children residing in Otash and AI Salaam camps.

\section{References}

1. Black RE, Allen LH, Bhutta ZA, Caulfield LE, de Onis M, et al. (2008) Maternal and child undernutrition: global and regional exposures and health consequences. Lancet 371: 243-260.

2. http://www.ennonline.net/pool/files/ife/m12-management-of-moderate-acutemalnutrition-entire-modeule.pdf

3. Vaitla B, Devereux S, Swan SH (2009) Seasonal hunger: a neglected problem with proven solutions. PLoS Med 6: e1000101.

4. Action Contre la Faim. (2008) Final Report. Nutritional Anthropometric and Retrospective Mortality Surveys. Children Aged 6 to 59 months. Al Salam IDP Camp. South Darfur State, Sudan. Fieldwork 21.

5. Action Contre la Faim. (2008) Preliminary Results: Nutritional anthropometric and retrospective mortality survey, Children 6 to 59 months. Otash IDP Camp, South Darfur State-Sudan. Dates of Survey.

6. http://reliefweb.int/node/418828
7. Action Contre la Faim. Final Report (2008) Nutritional Anthropometric and Retrospective Mortality Surveys. Children aged 6 to 59 months. Al Salam IDP camp. South Darfur State, Sudan. Dates of the survey: November 23-11 December, 2008

8. Shoham J, Duffield A (2009) Proceedings of the World Health Organization UNICEF/World Food Programme/United Nations High Commissioner fo Refugees Consultation on the management of moderate malnutrition in children under 5 years of age. Food Nutr Bull 30: S464-474.

9. http://www.who.int/nutrition/publications/moderate malnutrition/mm report/en/ index.html

10. http://www.nutriset.fr/en/product-range/produit-par-produit/plumpydoz.html 11. http://www.plosone.org/article/info:doi\%2F10.1371\%2Fjournal.pone.0005455

12. Isanaka S, Roederer T, Djibo A, Luquero FJ, Nombela N, et al. (2010) Reducing Wasting in Young Children With Preventive Supplementation: A Cohort Study in Niger. Pediatrics 126: e442-e450.

13. http://www.ncbi.nlm.nih.gov/pubmed/19225128

14. http://jn.nutrition.org/content/early/2010/09/22/jn.110.122499

15. http://www.wfp.org/nutrition/special-nutritional-products

16. USAID. (2006) Commodities Reference Guide Section II: Food Commodity Fact Sheets. Section II: Food Commodity Fact Sheets Corn Soy Blend2006.

17. United Nations, editor. How to Weigh and Measure Children, Assessing the Nutritional Status of Young Children in Household Surveys. New York: United Nations; 1986.

18. . http://www.who.int/childgrowth/training/module_h_directors_guide.pdf

19. Diggle PJ, Liang KY, Zeger SL. (1994) Analysis of Longitudinal Data. (1stedn) Oxford University Press, USA.

20. UNICEF. Darfur Nutrition Update: December 2006-Februray 2007. Issue 7 , 2007.

21. Epi Info version 6.04d. Atlanta, GA: Centers for Disease Control and Prevention; 2001.

22. Dean AG, Arner TG, Sunki CG, Friedman R, Lantinga M, et al. Epi Info ${ }^{\mathrm{TM}}$, a database and statistics program for public health professionals. C.Atlanta Georgia, USA: Centers for Disease Control and Prevention; 2007.

23. http://www.who.int/childgrowth/standards/technical_report/en/

24. Moser BE. Repeated Measures Modeling with PROC MIXED. Proceeding of the Twenty-Ninth Annual SAS ${ }^{\circ}$ Users Group International Conference Montreal, Canada: SAS Institute Inc; 2004. p. 188-29.

25. Littell RC, Henry PR, Ammerman CB (1998) Statistical analysis of repeated measures data using SAS procedures. J Anim Sci 76: 1216-1231.

26. http://support.sas.com/rnd/app/papers/miv802.pdf

27. Gelman A, Hill J. Data Analysis Using Regression and Multilevel/Hierarchical Models: Cambridge University Press; 2009.

28. Talley L. (2007) Rapid Nutritional Assessment , Darfur. September 15-23, 2007. Office of Foreign Disaster Assistance2007. 